\title{
VALORES DA EDUCAÇÃO E CRENÇAS NO DISCURSO PEDAGÓGICO OFICIAL DE GOVERNOS PORTUGUESES
}

\author{
(Values of education and beliefs in the official pedagogic discourse of Portuguese \\ governments)
}

Teresa Teixeira Lopo ${ }^{1}$ (Faculdade de Ciências Sociais e Humanas - Universidade Nova de Lisboa)

\begin{abstract}
In this article we present the model of analysis we have built, based on the works of Bronckart (1996, 2000, 2005a, 2005b, 2008) and Reboul (1984, 1999), to identify the decision process's guiding values of education and the beliefs associated with the impact of the education policy, invoked in the official pedagogic discourses of Portuguese governments. The results of that analysis, illustrated in this article with examples of the discursive production of constitutional governments with mandates initiated between 1978 and 2005, suggest the loss of value, in the definition of the communication space with the political parties, of educational values as references that influence the selection of the means and ends of the educational action.
\end{abstract}

Keywords: official pedagogic discourse, discourse analysis, values of education, beliefs, educational policy.

\section{RESUMO}

Neste artigo apresentamos o modelo de análise que construímos, com o apoio dos trabalhos de Bronckart (1996, 2000, 2005a, 2005b, 2008) e Reboul (1984, 1999), para identificar os valores da educação orientadores do processo de decisão e as crenças associadas ao impacto da política educativa, invocados nos discursos pedagógicos oficiais de governos portugueses. Os resultados dessa análise, ilustrada neste artigo com exemplos da produção discursiva de governos constitucionais com mandatos iniciados entre 1978 e 2005, sugerem a perda de valor, na delimitação do espaço de comunicação com os partidos políticos, dos valores da educação enquanto referências que influenciam a seleção dos meios e dos fins da ação educativa.

Palavras-chave: discurso pedagógico oficial, análise do discurso, valores da educação, crenças, política educativa.

\footnotetext{
${ }^{1}$ Licenciada em Sociologia, Mestre e Doutoranda em Ciências da educação, na especialidade Educação, sociedade e desenvolvimento, com tese sobre $A$ institucionalização das discussões nas ciências da educação no complexo parlamentar português (1976-2009), atualmente em fase de conclusão na Faculdade de Ciências Sociais e Humanas da Universidade Nova de Lisboa. Professora adjunta convidada da Escola Superior de Dança do Instituto Politécnico de Lisboa.
} 


\section{Introdução}

Neste artigo, recuperando resultados parcelares do trabalho de investigação que temos vindo a desenvolver sobre a decisão política em educação ${ }^{2}$, identificamos os valores da educação orientadores do processo de decisão e as crenças associadas ao impacto da política educativa, invocados nos discursos pedagógicos oficiais de governos portugueses.

Fazemo-lo, partindo dos seguintes pressupostos relativamente ao sentido dos conceitos de política educativa, valor e crença: uma noção de política educativa, que na sua dimensão pública remete para um processo, para crenças e esquemas interpretativos e de escolha de valores que definem a natureza dos problemas políticos e orientam a tomada de decisão (DURAN, 1996; MULLER, 2000; VAN ZANTEN, 2004); um conceito de valor assimilado ao fenómeno que é "experienciado como algo de "valioso", ao qual foi atribuída uma preferência maior no seu grau de importância face aos demais" (PEDRO, 2014, p.491); e, por fim, um conceito de crença entendida como maneira de fazer as coisas que se impõe como certeza, mesmo quando desprovida de qualquer fundamento científico concreto (BÉLANGER, 2008).

Neste enquadramento, para a inventariação dos valores da educação recorremos à teoria dos valores da educação de Reboul (1999), pela singularidade de propor uma axiologia própria da educação, enquanto as crenças foram, por nós, destacadas através de um trabalho exploratório sobre o corpus. A seleção desse corpus, que obedeceu ao critério de pertinência definido por Reboul (1984), que exclui do âmbito da análise material do discurso pedagógico oficial todos os documentos com carácter performativo (decretos, leis, circulares, etc.) integrou, nos exemplos que aqui trazemos, os programas com as principais orientações políticas e as medidas de governação a adotar sobre educação dos II, IX, XIII e XVII governos constitucionais portugueses e os discursos da sua apresentação aos partidos políticos com representação parlamentar na Câmara do parlamento português - a Assembleia da República. Utilizamos a expressão partidos políticos, em detrimento de deputados ou grupos parlamentares, considerando a posição de Miranda (2003, p.237) de que "a representação política hoje não pode deixar de estar ligada aos partidos (...). Pode dizer-se que o mandato parlamentar é (...) conferido tanto aos Deputados como aos partidos”.

\footnotetext{
${ }^{2}$ A autora agradece, no desenvolvimento desse trabalho na Faculdade de Ciências Sociais e Humanas da Universidade Nova de Lisboa, a estimulante orientação científica que tem recebido do Professor Doutor Luís Manuel Bernardo.
} 
Tomados estes textos como unidades comunicativas globais, utilizámos como suporte interpretativo, isto é, simultaneamente como modo de pensar o discurso e de tratar o discurso (NOGUEIRA, 2001), a análise do discurso perspetivada no quadro do interacionismo discursivo em que se inscrevem os trabalhos de Bronckart (1996, 2000, 2005b).

Sobre as fronteiras da análise do discurso, Gee (2011) salientou as diferenças entre as abordagens que "prestam mais atenção à estrutura da linguagem [...] e como esta estrutura funciona para fazer sentido em contextos específicos" (GEE, 2011, p.8, tradução nossa) e aquelas que olham para “o 'conteúdo' da linguagem utilizada, os temas ou questões em discussão" (GEE, 2011, p.8, tradução nossa). Interessando-nos este segundo enfoque, utilizámos como contextualizadores e organizadores da análise, respetivamente, as condições de produção dos textos e a organização temática da sua infraestrutura interna (BRONCKART, 1996, 2005a, 2008), ao nível dos grandes temas ou macro agregados conceituais em que se desdobraram esses textos (FONSECA, 1992): os valores da educação e as crenças.

No que respeita ao discurso especificamente pedagógico adotámos a abordagem de Reboul (1984) que o identifica como um tipo particular de discurso sobre a educação, diferente do discurso político e que visa sempre, independentemente do seu conteúdo, uma verdade de ordem prática, ou seja, destinada a justificar ou a julgar uma qualquer atividade que se assume como educativa. Já o discurso oficial, um tipo particular de discurso pedagógico, é definido como o discurso "dos homens que têm o poder para definir a pedagogia ou de a modificar na sua organização, nos seus conteúdos e nos seus métodos". 3

\section{Contributos do interacionismo sociodiscursivo para a análise do discurso pedagógico oficial}

O interacionismo sociodiscursivo aborda a ontogénese humana numa démarche descendente - isto é, focalizada nos efeitos específicos da história coletiva humana sobre a transformação permanente e correlativa dos factos sociais e dos factos psicológicos - que visa, não só, evidenciar o papel fundador da linguagem e, em particular, do funcionamento discursivo mas, também, os mecanismos de interação que atravessam os sistemas psicológico, da atividade social, da língua e o sistema textual-discursivo (BRONCKART, 2005a, 2005b).

Para Bronckart (1996) as propriedades específicas das condutas humanas constituem, assim, o resultado de um processo histórico de socialização em que formas particulares de

\footnotetext{
${ }^{3}$ Tradução livre da autora (REBOUL, 1984, p.43).
} 
organização social se desenvolveram ao mesmo tempo e, provavelmente sob o seu efeito, que formas de interação de carácter semiótico.

É neste contexto que o autor distingue um agir geral (não verbal) e um agir pela linguagem (agir verbal). $\mathrm{O}$ agir geral pode ser apreendido sob dois ângulos: por um lado, o das atividades coletivas (atividades gerais), enquanto estruturas de cooperação/colaboração que organizam o essencial das interações dos indivíduos com o meio e, por outro, o da ação (ação geral) de um ou vários indivíduos singulares. Por sua vez, o agir pela linguagem reporta-se quer a atividades de linguagem, cuja força maior será a de garantir o entendimento indispensável à realização das atividades gerais, quer à ação de linguagem, isto é, a uma "parte da actividade linguística cuja responsabilidade se encontra imputada [...] a um indivíduo singular, que se torna assim o agente ou autor" (BRONCKART, 2005a, p.57, itálico do autor).

É nas relações estabelecidas com o meio que as representações dos sujeitos são semiotizadas, tornando-se produto da interface entre representações individuais (ou tendo lugar numa só pessoa) e coletivas (ou tendo lugar nas obras humanas). É numa semiotização com estas características que emerge o agir propriamente pela linguagem, que se organiza em textos e/ou discursos.

Uma ação ou atividade de linguagem materializa-se, portanto, sob a forma de um texto (correspondente empírico/linguístico de uma dada ação de linguagem) ou de textos (correspondentes empíricos/linguísticos das atividades de linguagem de um grupo) que se constroem mobilizando recursos lexicais e sintáticos, tendo por referência os modelos de organização textual disponíveis numa dada língua natural. Contudo, ainda que um texto mobilize unidades linguísticas, não constitui em si mesmo uma unidade linguística. $\mathrm{Na}$ verdade, "as suas condições de abertura, de fechamento (e certamente de planificação geral) não relevam do linguístico, mas são inteiramente determinadas pela acção que o gerou; é a razão pela qual qualificamos o texto como unidade comunicativa" (BRONCKART, 2005a, p.58, itálico do autor). É por relação com este pressuposto, da globalidade discursiva, "em que as partes se definem do ponto de vista pragmático, conceptual e temático a partir do seu todo, e o todo a partir da conjugação das partes" (HÜSGEN, 2004, p.403) que situámos a nossa investigação, num percurso que procurando encontrar uma "continuidade de sentido" (FONSECA, 1992, p.31), só pode ser descendente: das atividades sociais para as atividades de linguagem, e destas para os textos e para os seus componentes linguísticos. 
As ações de linguagem desenvolvem-se num determinado contexto de produção, definindo por Bronckart (1996, p.95, tradução nossa) como o "conjunto de parâmetros suscetíveis de exercer influência sobre o modo como o texto é organizado". Nesses parâmetros, ou condições de produção dos textos, incluem-se as representações do agente sobre, por um lado, o quadro material ou físico de uma situação concreta de ação de linguagem, com identificação do lugar físico e do tempo da produção, do emissor (produtor) e do recetor e, por outro lado, sobre o quadro sociosubjetivo em que se inscreve a interação comunicativa. Este contexto implicando, simultaneamente, o mundo social (normas, valores, regras, etc.) e o mundo subjetivo (imagem que o produtor tem de si próprio ao agir), inclui o lugar social (formação social, instituição ou modalidade de interação em que o texto é produzido), os papéis discursivos que daí decorrem para o enunciador e destinatário, e uma relação de finalidade (efeito ou efeitos que o texto é capaz de produzir).

Quanto à arquitetura interna dos textos, Bronckart (1996, 2005a, 2008) propõe um modelo organizado em camadas superpostas com diferentes níveis de profundidade: no nível de maior superficialidade, os mecanismos enunciativos (responsabilidades enunciativas, vozes e pontos de vista, e modalizações), a seguir, no nível intermédio, os mecanismos de textualização (mecanismos de conexão e de coesão nominal) e, por fim, no nível de maior profundidade, a infraestrutura geral do texto. A infraestrutura geral do texto decompõe-se, por sua vez, na organização temática, em que centrámos o enfoque da nossa investigação discursiva, com identificação dos universos semânticos ou temas convocados no texto e respetiva planificação, e na organização discursiva, com identificação dos tipos de discurso e sequências.

No que respeita ao discurso especificamente pedagógico adotámos a abordagem de Reboul (1984) que, na definição do conceito, considerou três aceções: A usual ou corrente, que o fixa como "um conjunto coerente de frases, pronunciadas publicamente pela mesma pessoa sobre um determinado assunto", bem com as formuladas pela linguística em sentido restrito e alargado. (REBOUL, 1984, p. 9). No primeiro caso, o discurso pode ser definido como um conjunto de frases que formam uma mensagem com um princípio e um fim e, no segundo sentido, o que mais interessou ao autor para a caracterização desse tipo de discurso, trata-se de "um conjunto de discursos (em sentido restrito) proferidos por um mesmo indivíduo ou grupo social e apresentando características linguísticas comuns" (REBOUL, 1984, p.10) 
O discurso pedagógico, um dos discursos sobre a educação, diferencia-se do discurso político e visa sempre, independentemente do seu conteúdo, uma verdade. Esta verdade é de ordem prática, ou seja, destinada a justificar ou a julgar uma qualquer atividade que se assume como educativa. Na perspetiva de Bélanger (2008) esta é uma verdade que se apoia em crenças, isto é, em métodos ou maneiras de fazer que se impõem como uma evidência, mesmo quando desprovidas de qualquer fundamento científico concreto, por intermédio, nomeadamente, do discurso oficial.

O discurso oficial é apresentado na tipologia de Reboul (1984) como um tipo particular de discurso pedagógico que pode ser definido como o "dos homens que têm o poder para definir a pedagogia ou de a modificar na sua organização, nos seus conteúdos e nos seus métodos” (REBOUL, 1984, p.43, tradução nossa). É tipificado, independentemente de ser situado à esquerda ou à direita no espetro político, e das diferenças na organização temática que daí decorram, por um conjunto de traços em que se destacam o otimismo, a vontade reformista, o sincretismo, devendo a análise do seu conteúdo, num sentido estrito, material, excluir os aspetos performativos (leis, decretos, circulares, etc.) para somente se centrar nos textos que os explicam.

Os discursos, como explica Johnstone (2008, p.3), enquanto "formas ligadas de falar e de pensar, constituem ideologias (conjuntos de ideias interrelacionadas) e servem para fazer circular o poder na sociedade [...]. Discursos são ideias, bem como maneiras de falar que influenciam e são influenciadas pelas ideias”. Em linha com a constatação de Castro, Guimarães e Sancho (2007, p.74) de que "as acções educativas não podem ser tidas como processos neutros", para Reboul (1984), todos os discursos pedagógicos são ideológicos. A educação suscita discursos ideológicos por ser um desafio maior para o poder; o poder já estabelecido ou que se reivindica, mas que, em ambos os casos, esconde-se de forma implícita no discurso que visa secretamente legitimar.

Para van Dijk (1980, 1998, 2005) a ideologia é, em geral, uma forma de conhecimento social e a base das representações sociais de um grupo. Para Bélanger (2008), a ideologia que atravessa o discurso oficial sobre a educação é, justamente, a do governo e a do conjunto dos valores da sociedade a que este pertence. Sendo portador de um sistema de valores, o discurso pedagógico reflete o sistema social, a mudança e os novos valores que este vai incorporando mas, por que lhes dá forma, é também fundador dessas novas tendências. 
Resweber (2002) defendeu que sem valores não há comunicação possível. Os valores, enquanto referências que influenciam a seleção dos meios e dos fins da ação, articulam-se à delimitação a priori de um espaço de comunicação que cada encontro efetivo entre sujeitos confirma, infirma ou transforma. Servindo de elo intersubjetivo, os valores "contribuem para a descoberta da abertura e do horizonte de um mundo comum habitável" (RESWEBER, 2002, p.29) e, neste sentido, representam, simultaneamente, "referências necessárias à comunicação e figuras indispensáveis à expressão do desejo" (RESWEBER, 2002, p.31).

\section{Os valores da educação}

Na sua reflexão sobre os valores da educação, Reboul (1999) definiu o conceito de valor numa relação que implica, justamente, o desejo (que se sacrifica) e o sacrifício (que é desejado). O valor é aquilo que vale a pena, o que merece o sacrifício, possuindo a coisa sacrificada (a que se renuncia), ela própria um valor.

Reboul (1999) propôs uma axiologia própria da educação, que nos serviu para inventariar os valores da educação, que inclui, compatibiliza e releva, não só, os valores intelectuais mas, também, os valores morais e os valores estéticos. Nesta teoria dos valores da educação, que pelo seu contributo para pensar a educação tem vindo a ser resgatada por outros autores (JEDER, 2014; OGIEN, 2012; SODRÉ, 2012), é sublinhada a importância do curso, da lição imperfeita, em que se comunica um pensamento em construção. A par do curso e como meio, igualmente, privilegiado de acesso à verdade e à cultura, surge o livro. A leitura, ao mesmo tempo em que prolonga e aprofunda a preleção do mestre, deixa ao leitor a possibilidade de se abjugar.

São destacados também os valores do ser adulto (como evitamento do infantilismo), do equilíbrio (designando o crescimento humano, a possibilidade de elevação a um plano de maturidade superior), do normal (a educação deve suplantar o normal; deve ser capaz de formar para o normativo), do estudo metódico, do sucesso/insucesso, da rutura/continuidade, da cultura (como certa qualidade dos saberes que os torna ao mesmo tempo disponíveis, assimiláveis e comunicáveis) e do saber.

O saber é decomposto em três níveis. Os dois primeiros, o saber que (respeitante a informações) e o saber-fazer (respeitante a aptidões ou skills), orientando-se para finalidades externas não têm outro valor senão o de meios. Já no terceiro nível, em que se procura saber para saber/aprender o porquê, ou seja, compreender, o saber é um saber-fim, um saber em si 
mesmo. Compreender é um valor nuclear da educação intelectual, moral e estética. Como assinalou o autor, "um saber que nada mais tem a aprender, é um saber morto, tornado rotina (REBOUL, 1999, p.241, tradução nossa).

Reboul (1999) refuta a ideia de que a pretensão de um valor à universalidade dependa do grau de generalização da sua aceitação. A relatividade axiológica anularia o valor universal da própria educação. O universal plasma-se na humanidade, no encontro, isto é, na possibilidade de comunicar.

\section{3. $O$ contexto da governação política entre 1978 e 2005}

O quadro político-institucional, no arco temporal em que trabalhámos, foi marcado por dois traços principais. O primeiro, entre 1976 e 1987, período que cobre o exercício de funções do II e IX Governos constitucionais, caracterizado pela presença de um sistema partidário fragmentado (sistema polarizado multipartidário) e por uma instabilidade governativa crónica que as coligações/acordos entre partidos políticos se mostraram incapazes de resolver e que estiveram associadas, como explicou Magalhães (2005, p.190), "a dificuldades na aprovação e implementação de reformas [...] extremamente necessárias". Ao longo dessas duas décadas assistiu-se, por outro lado, a uma maior aproximação ideológica entre os partidos políticos à direita do comunismo sem que, contudo, essa fluidez ou esbatimento de diferenças se tenha imposto como igualdade ideológica (FREIRE, 2006, 2007; GUEDES, 2012).

O segundo, a partir de 1987, período que cobre o exercício de funções do XIII e XVII Governos constitucionais, em que se assiste a uma "abrupta viragem maioritária" (MAGALHÃES, 2005, p.173), tipificada pela redução do número de partidos significativos, a emergência de governos de partido único que se mantêm em exercício de funções até ao final da legislatura, e a alternância no poder entre o Partido Socialista (PS) e o Partido SocialDemocrata (PSD), os dois principais partidos centristas (sistema polarizado de dois partidos).

Relativamente às posições no espectro político desses partidos, considerando uma divisão entre esquerda e direita (Freire, 2006), o PSD ocuparia o centro-direita, delimitado à direita pelo Centro Democrático Social (CDS), com que o PS estabeleceu um acordo político para a formação do II Governo Constitucional, e que ocuparia, por seu turno, o centroesquerda. 
O quadro da definição das políticas educativas foi, por seu turno, marcado pelas seguintes três circunstâncias: A primeira, a adesão de Portugal à Comunidade Económica Europeia (CEE), de que Portugal se tornou membro em 1986, e as razões que a partir daí se invocam para justificar a prioridade e a reforma educativa.

A segunda, de institucionalização jurídica do projeto normativo da Lei de Bases do Sistema Educativo (LBSE), que definiu a estrutura do sistema nacional de educação português e os princípios orientadores do seu funcionamento e que depois da sua aprovação em 1986, acomodando e unificando interesses diversos, se tornou um quadro normativo estável a partir do qual se podem pensar as políticas educativas.

Por fim, a terceira, relativa à assinatura da Declaração de Bolonha em 1999, e o processo complexo de reforma que daí decorrerá e que, como assinalou Antunes (2007, p.3), corresponderá a "uma dinâmica radicalmente nova de mudança educacional e de elaboração de políticas".

\section{A investigação discursiva}

Apresentaremos, seguidamente, exemplos ilustrativos da análise realizada, começando pelo II Governo Constitucional, que tomou posse a 23 de janeiro de 1978 e se constituiu com base numa coligação (acordo político) entre o PS e o CDS. Na apresentação na Assembleia da República (AR) das medidas de política educativa aos partidos políticos com representação parlamentar, o ministro da Educação e Cultura enunciou, num quadro em que a educação se articulou à consolidação e desenvolvimento da democracia, as soluções pensadas pelo governo para resolver os "problemas capitais do sistema escolar" (PORTUGAL, 1978, p.1331). Desse conjunto de soluções, Sottomayor Cardia deu saliência às ações programáticas de planeamento (estudos) e também às dirigidas à definição normativa (produção e aperfeiçoamento de regulamentos, estatutos e leis) e organização geral (articulação de diferentes competências, entidades e recursos pela gestão do Estado), acreditando nos seus benefícios, para regrar, arrumar e estabilizar a organização e o funcionamento do sistema escolar, bem como, o acesso à profissão e ao desenvolvimento profissional, bem como a carreira dos professores.

Numa lógica de construção da justiça educativa em torno do princípio da igualdade de oportunidades de acesso aos saberes escolares, o ministro da Educação e Cultura, separando claramente o escolar (pela valorização do curso) e o não escolar, focalizou-se no currículo 
para mobilizar um conjunto de valores da educação. Relevou nos critérios de seleção dos conteúdos, a sua organização para uma aplicação utilitária no ensino preparatório e nos cursos geral e complementar do ensino secundário. Esta valorização das componentes vocacional e profissionalizante do ensino, da aptidão para agir (saber fazer) dos saberes escolares, visava tornar o aluno "de algum modo preparado para trabalhar como trabalhador e não como aprendiz totalmente desqualificado". Só estreitando esta relação entre educação e trabalho seria possível, sublinhou, "acautelar a inserção na vida activa" de quantos, sobretudo "os mais socialmente desfavorecidos", abandonam precocemente a escola (PORTUGAL, 1978, p. 1328-1329).

Diferentemente, no ensino primário, em que alcançam valor o equilíbrio (como possibilidade de o ensino conduzir o aluno a um plano de maturidade superior), o ser adulto (como evitamento à infantilização dos conteúdos de ensino) e o papel educador do professor, as intenções educativas devem ser concretizadas através de saberes substantivos (saber para saber - compreender), assim o justificando o ministro da Educação e Cultura Sottomayor Cardia:

\begin{abstract}
Criou-se um certo constrangimento entre não poucos professores. A desorientação é visível. Não se exige pelo receio de 'traumatizar'; confina-se o ensino ao estritamente concreto, como se tal não bloqueasse pura e simplesmente o desenvolvimento intelectual das crianças. Uma escola não será positivamente apenas um lugar de recreio. Digo-o com todo o respeito pela necessária inovação pedagógica: mas é exactamente em defesa dessa exigência que não deve pactuar-se com o culto da facilidade e da preguiça. (PORTUGAL, 1978, p.1328).
\end{abstract}

Em síntese, no quadro da definição da contribuição da educação para a consolidação e desenvolvimento da democracia em que o projeto político do II Governo Constitucional se inscreveu, a política educativa a prosseguir deveria ser capaz de garantir a governabilidade de uma escola que constrói a justiça educativa em torno do princípio da igualdade de oportunidades de acesso aos saberes escolares, se baseia numa ordem jurídica e administrativa estabilizada pela intervenção e gestão do Estado, e num núcleo duro de valores da educação, enquanto referências que influenciam a seleção dos meios e dos fins da ação educativa.

O segundo exemplo de análise que apresentamos é relativo ao IX Governo Constitucional, uma coligação pós-eleitoral (acordo político) entre o PS e o PSD, que se formou com base nos resultados das eleições realizadas a 25 de abril de 1983.

$\mathrm{Na}$ apresentação na AR das medidas de política educativa aos partidos, o ministro da Educação José Augusto Seabra centrou-se no tema da adequação da política educativa a um 
contexto de crise económica, social e cultural e em que se tornava necessário, igualmente, modernizar as estruturas produtivas e adaptá-las ao desafio da integração europeia. Neste contexto foi elencada como prioridade maior a institucionalização das vias profissionalizantes e profissional através de um plano de emergência para a reorganização do ensino técnico. Plano que não obstante valorizar o saber que e o saber para saber/compreender acabou por afirmar o valor do saber-fazer num itinerário assim explicado pelo ministro da Educação:

\footnotetext{
Não se trata de pôr de modo nenhum em causa o direito a uma formação geral comum, que o ensino unificado consagrou, mas de introduzir pouco a pouco, primeiro, uma iniciação às ferramentas técnicas, ao lado das ferramentas intelectuais, umas e outras inerentes a uma educação harmoniosa, e depois uma formação profissional efectiva, sem prejuízo de uma igualdade de oportunidades no acesso ao ensino superior, dando toda a devida importância ao ensino superior politécnico, ao lado do universitário propriamente dito (PORTUGAL, 1983, p.231).
}

Situando a filosofia do programa do governo como "voltada antes de mais para a Juventude, para as gerações emergentes", visando transmitir-lhes "os valores civilizacionais que nos definem como povo e constituem a nossa identidade nacional, formando antes de mais a personalidade de cada cidadão, na pluralidade das suas convicções, crenças e maneiras de ser" (PORTUGAL, 1983, p.230), também o valor do aluno e da sua participação na gestão democrática da escola foi afirmado, bem como, a possibilidade de o formar para além do normal, como homem normativo.

Foi valorizado, igualmente, o curso e o professor. Aos "principais obreiros da Educação", a estes "cidadãos que exercem a mais digna e nobre das funções sociais: a de fazer das nossas crianças, dos nossos jovens, os homens e cidadãos do futuro", o ministro prometeu a sua dignificação e valorização social, através de ações programáticas dirigidas à sua carreira e à sua formação e desenvolvimento (PORTUGAL, 1983, p.231).

O ministro da Educação defendeu, ainda, a consolidação e a diversificação das formações escolares e não escolares (presenciais e a distância) acreditando no contributo benéfico destas ações para a implementação do princípio da igualdade de oportunidades. Foram defendidas, adicionalmente, as ações destinadas a reforçar o papel do ensino particular e cooperativo e o seu impacto para a implementação do princípio da liberdade do ensino e, com menor relevância, as ações programáticas dirigidas à desconcentração e descentralização dos serviços do Ministério da Educação e à promoção da investigação, centrada nas 
universidades, e a articular ao desenvolvimento regional e nacional do país (PORTUGAL, 1983).

O ministro da Educação terminou a sua apresentação referindo-se, tal como o seu predecessor do II Governo Constitucional, à urgência da promoção de um debate público sobre as questões fulcrais do ensino, de que possa resultar uma lei de bases do sistema educativo que "pela sua largueza de princípios, e de valores, o seu rigor jurídico e o seu pragmatismo político, fique a constituir um marco histórico do nosso Parlamento" (PORTUGAL, 1983, p.222-223).

Em síntese, neste segundo exemplo, no quadro da definição da contribuição da educação para a modernização e o crescimento económico em que o projeto político do IX Governo Constitucional se inscreveu, tratou-se de garantir a governabilidade de uma escola que constrói a justiça educativa em torno do princípio da igualdade de oportunidades de acesso e da liberdade de ensinar. Enquanto referências que influenciaram a seleção dos meios e dos fins da ação, valorizou-se o curso e o professor, a possibilidade de formar um homens e mulheres normativos para quem, num percurso de formação em que se vai afirmando o saberfazer, a educação deveria ser capaz de criar oportunidades de emprego.

O terceiro exemplo que, aqui, apresentamos é relativo ao XIII Governo Constitucional, formado com base nos resultados das eleições legislativas realizadas a 1 de outubro de 1995 e que conferiram uma maioria relativa ao PS.

$\mathrm{Na}$ apresentação do programa do governo na AR aos partidos políticos, o Primeiroministro António Guterres explicou como se articulará a educação com outras políticas, numa rede de complementaridades:

\footnotetext{
Uma educação coordenada com a formação profissional [...]. Uma educação que é produto de uma cultura, mas factor decisivo de valorização dessa mesma cultura [...]. Uma educação que é condição de eficácia para a investigação científica e tecnológica, mas cuja eficácia exige a qualidade científica do ensino, vivendo paredes meias com a investigação. (PORTUGAL, 1995a, p.36).
}

O Primeiro-ministro antecipou, ainda, nesta apresentação, o conjunto dos benefícios esperados/impacto da política educativa a prosseguir e que serão, como veremos de seguida, arrolados e articulados a ações programáticas pelo ministro da Educação Marçal Grilo: garantir uma educação para todos, aumentar a qualidade e a justiça (equidade), a responsabilização dos serviços públicos de educação e a participação ativa da sociedade. 
$\mathrm{Na}$ sua apresentação do programa do governo sobre educação, Marçal Grilo valorizou o contributo da educação para a eficácia social; aliando no discurso pedagógico oficial a educação ao desenvolvimento, justificou a prioridade dada à educação como "uma exigência da sociedade aberta de conhecimento e informação em que vivemos, na qual as qualificações pessoais constituem as melhores vantagens comparativas" (PORTUGAL, 1995b, p.115).

Enunciou depois, articulando a participação à democratização e elegendo a primeira como seu fundamento, o tema do Pacto Educativo e dos alicerces que deverão sustentar a sua celebração: negociado numa geometria variável, com parceiros sociais e educativos, de decisão participada (para as tarefas, as responsabilidades, os direitos e os deveres) e envolvendo toda a comunidade. Explicou a seguir o edifício: partindo da complexidade e heterogeneidade dos problemas, apontou soluções de desenvolvimento da educação e da melhoria da sua qualidade que procuraram enlear diferentes orientações, objetivos, compromissos e valores. Como detalhou:

A complexidade do nosso tempo obriga a ligar liberdade e justiça através da diversidade - em nome da autonomia individual e da solidariedade voluntária e responsabilizadora. 'Escolas para o Século XXI' - eis um projecto aberto que estamos a preparar e que poderá constituir um incentivo à criação de comunidades educativas, onde a cidadania e a qualidade de vida, o diálogo de saberes e a compreensão do mundo e da vida possam cruzar-se e ser devidamente valorizados. (PORTUGAL, 1995b, p.115).

Este projeto, para além da necessária coordenação com outras políticas (qualificação, emprego, ciência, tecnologia e cultura), ambiciona também ampliar relações (entre lugares para e da educação, saberes e protagonistas do processo educativo). Neste contexto, como enunciou:

Não podemos esquecer os pais, as famílias, os autarcas, as organizações nãogovernamentais, a vida associativa - em suma, a sociedade civil - têm a maior importância numa nova relação que tem de se estabelecer entre a escola e a vida. A escola deverá, assim, existir com as portas abertas à sociedade. A educação permanente para todos [...] obriga a essa nova relação entre educação formal e não formal, sem fronteiras rígidas nem muros (PORTUGAL, 1995b, p.115).

É no meio desta malha de elencos, ou na imagem de Correia (2000), de uma escola atarefada, que são introduzidos, entre laçadas que acabam por os diluir, os valores da educação: do professor motivado, ativo, criador e competente, com condições de carreira e desempenho das tarefas educativas que lhe proporcionem estabilidade e dignidade, do equilíbrio, pela continuidade educativa do pré-escolar ao ensino superior e da cultura, através, 
nomeadamente, de um currículo que alie a dimensão cultural, artística e o ensino experimental.

Marçal Grilo numa lógica que inscreve a democratização e a excelência como faces da mesma moeda centrou-se, ainda, no impacto esperado da política educativa a prosseguir: elevar a equidade, a qualidade e a eficácia no processo educativo. Benefícios a alcançar através de um conjunto de ações programáticas de cariz funcionalista, como por exemplo, as de replicar as boas práticas de escolas identificadas como centros de excelência, implementar um sistema de avaliação do ensino independente para divulgação pública dos resultados alcançados, introduzir no ensino particular e cooperativo novos padrões de rigor e qualidade e descentralizar responsabilidades (para as autarquias e regiões administrativas), para chamar a Administração à "eficácia, à prestação de contas e à proximidade dos cidadãos" (PORTUGAL, 1995b, p.115).

O XVII Governo Constitucional, governo que se formou com base nos resultados das eleições legislativas de 20 de fevereiro de 2005 que conferiram uma maioria absoluta ao PS, é o nosso último exemplo ilustrativo. Na apresentação do programa do governo na $\mathrm{AR}$, o Primeiro-ministro José Sócrates assumiu o Plano Tecnológico como a primeira prioridade da ação política. Apresentou-o, não só, como “a mais estruturada proposta política para o desenvolvimento do País lançada nos últimos anos” (PORTUGAL, 2005, p.46) mas, também, como uma resposta integrada, na articulação entre conhecimento, inovação e tecnologia, ao problema do défice das qualificações.

No âmbito deste Plano que visava mobilizar o país como um todo (empresas, administração pública, escolas, sistema científico e tecnológico e estudantes), a melhoria do sistema de educação/formação, o combate ao abandono e ao insucesso escolar, e a valorização do ensino tecnológico e profissional seriam, como explicou o Primeiro-ministro, "algumas das tarefas que o Governo abraçará com especial determinação" (PORTUGAL, 2005, p.46).

$\mathrm{Na}$ apresentação do programa de governo na AR aos partidos políticos não participou a ministra da Educação Maria de Lurdes Rodrigues.

Coube, assim, ao Ministro da Ciência, Tecnologia e Ensino Superior apresentar o Plano Tecnológico, "um programa ambicioso e exigente para o nosso desenvolvimento tecnológico e científico, para o progresso na educação, na formação e na inovação" (PORTUGAL, 2005, p.120), destacando os pilares em torno dos quais se estrutura. Para o ensino, a cultura científica dos que frequentam a escola (condição de progresso económico, 
cultural e social) e a cultura de abertura internacional (decorrente da concretização do processo de Bolonha, como condição necessária para qualificar para as exigências do espaço europeu e como oportunidade de diversificação e de autonomia responsável para universidades e politécnicos). Para a ciência, constituindo-se em conjunto com a cultura de abertura internacional, como pilares "do pensamento crítico e livre e da vida democrática" (PORTUGAL, 2005b, p.120), a cultura de verdade e a cultura de avaliação.

Plano que, como relevou o Ministro da Ciência, Tecnologia e Ensino Superior, "o progresso do País exigia" e que adotaria para Portugal, "a exigência de um rumo: estudar mais, saber mais, cooperar mais, saber fazer melhor" (PORTUGAL, 2005, p.122). Mariano Gago identificou, ainda, os eixos que o sustentariam: formar e qualificar, generalizar o uso das tecnologias de informação e comunicação na vida económica e social imprimindo um novo impulso à inovação e vencer o atraso científico e tecnológico, bem como, as suas metas:

\footnotetext{
A redução para metade do insucesso escolar nos ensinos básico e secundário, a duplicação dos jovens em cursos tecnológicos e profissionais de nível secundário e a generalização de escolhas curriculares apropriadas, designadamente de natureza técnica e vocacional, para além da obrigatoriedade de formação profissional ou de frequência escolar até aos 18 anos, do aumento de diplomados e formações avançadas do ensino superior. A obrigatoriedade, finalmente, do ensino experimental das ciências e a diversificação de oportunidades de formação, com ênfase na valorização de aprendizagens práticas e na aquisição de competências técnicas. (PORTUGAL, 2005, p.120).
}

Em síntese, com a educação fora de cena, é em torno das entidades mitificadas da ciência e da tecnologia e das suas funções imperativas para o progresso humano que se organiza o discurso pedagógico oficial de Mariano Gago. O saber científico, glorificado, ocupa o espaço de quase todo o saber, dilui os recursos culturais e subordina os valores-meios do mais saber que e do saber-fazer melhor a uma finalidade instrumental imediata: qualificar para o trabalho.

\section{Considerações finais}

A investigação discursiva, respaldada pelo modelo construído, permitiu-nos identificar os temas, os valores da educação orientadores do processo de decisão e as crenças associadas ao impacto da política educativa, invocados nos discursos pedagógicos oficiais de governos portugueses e analisar as alterações que se configuraram, ao longo do tempo, na seleção dessas maneiras de fazer e referências. 
Os resultados mais salientes dessa análise podem ser aglutinados em torno de três grandes tendências. A primeira, correspondente aos governos que iniciaram os seus mandatos entre 1978 e 1983 (II e IX Governos Constitucionais), em que os discursos pedagógicos oficiais se organizam em torno das crenças associadas ao impacto das ações programáticas intencionadas pelos governos e de um conjunto reduzido de valores, em que os valores da educação predominam e delimitam o espaço de comunicação com os partidos políticos com representação parlamentar.

A segunda, correspondente ao do governo que iniciou o seu mandato em 1995 (XIII Governo Constitucional), em que o discurso pedagógico oficial se organiza em torno das crenças associadas ao impacto das ações programáticas de reforma educativa intencionada pelo governo. Quanto aos valores invocados, ocultando que a definição da política educativa implica sempre uma escolha, o discurso pedagógico oficial encheu-se de valores, perdendo valor, por conseguinte, enquanto referências que influenciam a seleção dos meios e dos fins da ação educativa, os valores da educação, num efeito registado por Brito e Meneses (2010, p.5): "se os valores tivessem todos o mesmo valor, tudo valeria a mesma coisa, o que levaria à conclusão de que nada valia coisa nenhuma”.

Finalmente, com o XVII Governo Constitucional, que iniciou o seu mandato em 2005, a educação deixa de ter um projeto próprio. O discurso pedagógico oficial organizado em torno das crenças associadas ao impacto da implementação do Plano Tecnológico, e das entidades glorificadas da ciência e da tecnologia e das suas funções imperativas para o progresso humano, esvaziou-se de valores da educação, determinando para os que remanescem, numa relação que se foi estreitando ao longo do tempo de desvalorização do saber para saber/compreender e de uma correlata valorização do saber-fazer, uma finalidade instrumental: qualificar para o trabalho, a modernização e, por essas vias, para a competitividade económica.

Recebido em: agosto de 2015

Aprovado em: abril de 2016

ttlopo@gmail.com 


\section{Corpus documental}

PORTUGAL. Debate do programa do II governo constitucional. Diário da Assembleia da República, Lisboa, n. 38, I Série, de 11 de fevereiro de 1978. Disponível em: <http://debates.parlamento.pt/catalogo/r3/dar/01/01/02/038/1978-02-10> Acesso em: 13 jul.2015.

. Debate do programa do IX governo constitucional. Diário da Assembleia da República, Lisboa, n.9, I Série, 25 de junho de 1983. Disponível em: <http://debates.parlamento.pt/catalogo/r3/dar/01/03/01/009/1983-06-24> Acesso em: 13 jul.2015.

Apresentação do programa do XIII governo constitucional pelo primeiroministro António Guterres. Diário da Assembleia da República, Lisboa, n.3, I Série, de 8 de novembro 1995a, p.33-38. Disponível em: <http://debates.parlamento.pt/catalogo/r3/dar/01/07/01/003/1995-11-07/31> Acesso em: 13 jul.2015.

. Debate do programa do XIII governo constitucional. Diário da Assembleia da República, Lisboa, n.4, I Série, de 10 de novembro de 1995b. Disponível em: <http://debates.parlamento.pt/catalogo/r3/dar/01/07/01/004/1995-11-09> Acesso em: 13 jul.2015.

Apresentação e debate parlamentar do programa do XVII governo constitucional. Diário da Assembleia da República, Lisboa, n.3, I Série, de 22 de março de 2005, p.43-54. Disponível em: <http:/debates.parlamento.pt/catalogo/r3/dar/01/10/01/003/2005-03-21/39> Acesso em: 13 jul.2015.

\section{Referências bibliográficas}

ANTUNES, F. O espaço europeu de ensino superior para uma nova ordem educacional? ETD - Educação Temática Digital, Campinas, vol. 9, n. esp., p.1-28, dez. 2007. Disponível em: <https://www.fe.unicamp.br/revistas/ged/etd/article/view/1699>. Acesso em: 4 jul. 2015

BÉLANGER, A. Analyse critique des valeurs explicites et implicites du discours de la réforme en éducation au Québec. 2008. 177p. Dissertação (Mestrado em Educação) Universidade do Québec, Montreal. Disponível em: 〈http://www.archipel.uqam.ca/1281/> Acesso em: 6 jul. 2015.

BRITO, J.H.S.; MENESES, R.D.B. Os valores e a antropologia: para uma leitura fenomenológica", Eleutheria, cidade de Guatemala, n.2, p.1-20, jun./set. 2010. Disponível em: <http://www.eleutheria.ufm.edu/ > Acesso em: 10 jul. 2015.

BRONCKART, J.-P. Activité langagière, textes et discours: pour un interactionnisme sociodiscursif. Lausanne: Delachaux et Niestlé, 1996.

Possibles de l'activité langagière et impossibles de "la langue".

Sémiotiques, Paris, n.18-19, p.153-172, dez. 2000. 
Os géneros de textos e os tipos de discurso como formatos das interacções de desenvolvimento. In: ANSCOMBRE, J.-P.; BRONCKART, J.-P.; MAINGUENEAU, D. (Orgs.). Análise do discurso. Lisboa: Hugin, 2005a, p.37-79.

- Les différentes facettes de l'interactionnisme socio-discursif. Calidoscópio, São Leopoldo, vol.3, n.3, p.149-159, set./dez. 2005 b.

Genres de textes, types de discours e "degrés" de langue. Hommage à François Rastier, Texto!, Paris, vol.13, n.1, p.1-95, jan. 2008. Disponível em: <http://www.revue-texto.net/index.php?id=86> Acesso em: 6 jul. 2015

CASTRO, R. V.; GUIMARÃES, P.; SANCHO, A. V. Mutações no campo da educação de adultos. Sobre os caminhos da formação dos educadores. Educar, Curitiba, n. 29, p. 63-81, 2007.

CORREIA, J. A. As ideologias educativas em Portugal nos últimos 25 anos. Porto: Asa, 2000 .

DURAN, P. L'analyse des politiques publiques en perspective, de la crise de la politique à sa reconstruction. Revue Française de Science Politique, Paris, vol.46, n.1, p.108-118, fev. 1996.

FONSECA, J. Línguística e texto/discurso: teoria, descrição, aplicação. Lisboa: Ministério da Educação, Instituto de Cultura e Língua Portuguesa, 1992.

FREIRE, A. Esquerda e direita na política europeia: Portugal, Espanha e Grécia em perspectiva comparada. Lisboa: Imprensa de Ciências Sociais, 2006, 368p.

FREIRE, A. Identidades ideológicas: Portugal, Espanha e Grécia em perspectiva comparada. In: VIEGAS, J.M.L; CARREIRAS, H.; MALAMUD, A. (Orgs.). Portugal no contexto europeu. Instituições e política. Oeiras: Celta Editora, 2007, p. 37-58.

GEE, J. P. An introduction to discourse analysis: theory and method. New York: Routledge, 2011.

GUEDES, N. Convergência ideológica? Uma análise comparada dos programas eleitorais do PS e do PSD (1991-2009). Sociologia, Problemas e Práticas, Lisboa, n. 68, p.103-125, jan./abr. 2012.

HÜSGEN, T.J.C. Coerência textual e tradução. In: OLIVEIRA, F.; DUARTE, I.M. (Orgs.). Da língua e do discurso. Porto: Campo das Letras, 2004, p. 403-415.

JEDER, D. Training trainers through education practice towards values and civility. Procedia - Social and Behavioral Sciences, Amsterdão, v.116, p.1958-1962, fev. 2014.

JOHNSTONE, B. Discourse analysis. Oxford: Wiley-Blackwell, 2008.

MAGALHÃES, P. Eleições, partidos e instituições políticas no Portugal democrático. In: PINTO, A.C. (Org.). Portugal contemporâneo. Lisboa: D. Quixote, 2005, p. 173-192. 
MIRANDA, J. O parlamento de Portugal. Revista de Informação Legislativa, Brasília, v.40, n.159, p.225-240, jul./set. 2003.

MULLER, P. (2000). L'analyse cognitive des politiques publiques: vers une sociologie politique de l'action publique. Revue Française de Science Politique, Paris, vol.50, n.2, p. 189-208, abr.2000.

NOGUEIRA, C. A análise do discurso. In: ALMEIDA, L.S.; FERNANDES, E.M. (Orgs.), Métodos e técnicas de avaliação: novos contributos para a prática e investigação. Braga: Centro de Estudos em Educação e Psicologia, 2001, p.15-48.

OGIEN, R. Repenser les relations entre les faits, les normes et les valeurs. Les Sciences de l'Éducation Pour l'Ère nouvelle, vol. 45, n.1, p. 17-31, 2012.

PEDRO, A.P. Ética, moral, axiologia e valores: confusões e ambiguidades em torno de um conceito comum. Kriterion, Belo Horizonte, vol.55, n.130, p.483-498, dez. 2014. Disponível em: <http://www.scielo.br/scielo.php?pid=S0100-512X2014000200002\&script=sci_arttext > Acesso em: 10 jul. 2015.

REBOUL, O. Le langage de l'éducation. Analyse du discours pédagogique. Paris: Presses Universitaires de France, 1984.

. Les valeurs de l'éducation. Paris: Presses Universitaires de France, 1999.

RESWEBER, J.-P. A filosofia dos valores. Coimbra: Almedina, 2002.

SODRÉ, M. Reinventando a educação. Diversidade, descolonização e redes. Petrópolis: Editora Vozes, 2012.

VAN DIJK, T. A. Algunas notas sobre la ideología y la teoría del discurso. Semiosis, Xalapa, n.5, p.37-53, jul./dez. 1980.

Ideology. A multidisciplinary approach. London: Sage, 1998.

.Ideología y análisis del discurso. Utopìa y Praxis Latinoamericana, Maracaibo, v. 10, n. 29, p. 9-36, jun. 2005.

VAN ZANTEN, A. Les politiques d'éducation. Paris: PUF, 2004. 